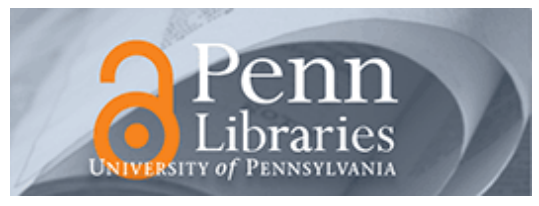

University of Pennsylvania

ScholarlyCommons

Marketing Papers

Wharton Faculty Research

3-2001

\title{
Medical Innovation Revisited: Social Contagion versus Marketing Effort
}

Christophe Van den Bulte

University of Pennsylvania

Gary L. Lilien

Follow this and additional works at: https://repository.upenn.edu/marketing_papers

Part of the Marketing Commons

Recommended Citation

Bulte, C., \& Lilien, G. L. (2001). Medical Innovation Revisited: Social Contagion versus Marketing Effort. American Journal of Sociology, 106 (5), 1409-1435. http://dx.doi.org/10.1086/320819

This paper is posted at ScholarlyCommons. https://repository.upenn.edu/marketing_papers/430

For more information, please contact repository@pobox.upenn.edu. 


\title{
Medical Innovation Revisited: Social Contagion versus Marketing Effort
}

\begin{abstract}
This article shows that Medical Innovation-the landmark study by Coleman, Katz, and Menzel-and several subsequent studies analyzing the diffusion of the drug tetracycline have confounded social contagion with marketing effects. The article describes the medical community's understanding of tetracycline and how the drug was marketed. This situational analysis finds no reasons to expect social contagion; instead, aggressive marketing efforts may have played an important role. The Medical Innovation data set is reanalyzed and supplemented with newly collected advertising data. When marketing efforts are controlled for, contagion effects disappear. The article underscores the importance of controlling for potential confounds when studying the role of social contagion in innovation diffusion.

Disciplines

Business | Marketing
\end{abstract}




\title{
Medical Innovation Revisited: Social Contagion versus Marketing Effort ${ }^{1}$
}

\author{
Christophe Van den Bulte \\ University of Pennsylvania
}

Gary L. Lilien

Pennsylvania State University

This article shows that Medical Innovation-the landmark study by Coleman, Katz, and Menzel—and several subsequent studies analyzing the diffusion of the drug tetracycline have confounded social contagion with marketing effects. The article describes the medical community's understanding of tetracycline and how the drug was marketed. This situational analysis finds no reasons to expect social contagion; instead, aggressive marketing efforts may have played an important role. The Medical Innovation data set is reanalyzed and supplemented with newly collected advertising data. When marketing efforts are controlled for, contagion effects disappear. The article underscores the importance of controlling for potential confounds when studying the role of social contagion in innovation diffusion.

\section{INTRODUCTION}

Researchers from various disciplines have long studied how innovations diffuse through populations of individuals, households, and organizations.

\footnotetext{
${ }^{1}$ We benefited from comments by Wayne Baker, Hans Baumgartner, Albert Bemmaor, the late Clifford Clogg, Jehoshua Eliashberg, Elihu Katz, David Krackhardt, Keith Ord, Arvind Rangaswamy, David Schmittlein, David Strang, Thomas Valente, Susan Watkins, the AJS reviewers, and audience members at the 1999 INSNA Sunbelt Conference, the 1994 and 1998 INFORMS Marketing Science Conferences, the Australian Graduate School of Management, Carnegie Mellon University, Columbia University, Cornell University, Duke University, Harvard University, Catholic University of Leuven, University of Michigan, Northwestern University, Pennsylvania State University, Stanford University, University of North Carolina at Chapel Hill, University of Texas at Austin, and the Wharton School. We thank Thomas Valente for providing us with the Medical Innovation data set prepared by Ronald Burt. Financial support from Penn State's Institute for the Study of Business Markets and the Richard D. Irwin
}

(C) 2001 by The University of Chicago. All rights reserved.

0002-9602/2001/10605-0006\$02.50

AJS Volume 106 Number 5 (March 2001): 1409-35

1409 
American Journal of Sociology

Sociologists have offered the important insight that innovation diffusion may be driven by social contagion - another way of saying that actors' adoption behavior is a function of their exposure to other actors' knowledge, attitude, or behavior concerning the innovation. Researchers have offered different theoretical accounts of social contagion, each describing a different causal mechanism of social influence.

Information transfer.-The social influence process may simply consist of information transfer. Actors may become aware of the existence of the innovation through word of mouth from previous adopters (Katz and Lazarsfeld 1955). Actors may also update their beliefs about the costs and benefits of adopting the innovation after discussing it with previous adopters or after observing the outcomes of adoption (e.g., increased status or profits). Bayesian updating through social learning under risk aversion (e.g., Chatterjee and Eliashberg 1990; Roberts and Urban1988) and Bandura's (1986) vicarious learning and modeling concepts are examples of this influence process, as is the modeling process posited by DiMaggio and Powell (1983).

Normative pressures.-The social influence process may take the form of normative pressures, such as when actors experience dissonance and hence discomfort when peers whose approval they value have adopted an innovation, but they have not (e.g., Coleman, Katz, and Menzel 1966; Davis, Bagozzi, and Warshaw 1989; DiMaggio and Powell 1983).

Competitive concern.-Social contagion may also be driven by the competitive concern that one's rivals who have adopted the innovation might be able to gain a competitive edge unless one adopts as well (e.g., Burt 1987; Hannan and McDowell 1987).

Performance network effect.- Some innovations exhibit a performance network effect when the benefits of use, and hence of adoption, increase with the number of prior adoptions. This effect may be direct, as with point-to-point communication devices like telephones and fax machines, but it may also be indirect, operating through the increased supply of complementary products, as with videocassette recorders and prerecorded tapes (Katz and Shapiro 1994), or through the increased supply of supporting infrastructure, such as video rental stores (Brown 1981; Delacroix and Rao 1994). ${ }^{2}$

Although these social contagion mechanisms are conceptually distinct,

Foundation is gratefully acknowledged. Direct correspondence to Christophe Van den Bulte, Wharton School, University of Pennsylvania, 3620 Locust Walk, Philadelphia, Pennsylvania 19104-6371. E-mail: vdbulte@wharton.upenn.edu

${ }^{2}$ Some may prefer to label such indirect endogenous feedback mediated through suppliers' decisions "ecological influence" rather than "social contagion" to distinguish it from more direct interpersonal or interorganizational influence (Marsden and Friedkin 1994). 


\section{Contagion versus Marketing}

their expressions in data may often be indistinguishable, making it impossible to identify the exact nature of the mechanism at work (DiMaggio and Powell 1983; Montgomery and Casterline 1996). In this article, we emphasize and empirically illustrate another fundamental challenge in the study of social contagion in innovation diffusion processes: how social network effects may be confounded with common contextual effects.

The danger of confounding common contextual effects for social contagion has long been recognized (e.g., Collier and Messick 1975; Erbring and Young 1979; Taibleson 1974). Classic studies by Katz and Lazarsfeld (1955) and Coleman et al. (1966), for instance, documented that awareness of and attitude toward new products can be affected not only by social contagion but also by mass media exposure and by companies' marketing efforts. More recent research has further challenged the empirical support for the role of social contagion in innovation diffusion by showing that S-shaped diffusion curves-often interpreted as evidence of social contagion-can result from population heterogeneity rather than contagion (Bemmaor 1994; Bonus 1973; Thirtle and Ruttan 1987). For instance, when a product's price decreases linearly over time and reservation prices are normally distributed over the population, the diffusion curve will be the normal cumulative density function. These results support concerns voiced by England (1998) and Haunschild and Miner (1997) that the positive relationship between the prevalence of prior adoption among one's network alters and the likelihood of one's own adoption-typically interpreted as evidence of social contagion-is often produced by factors that grow over time but that are excluded from the model. ${ }^{3}$

This article provides additional support for such concerns about confounding social contagion with the effect of omitted contextual variables. We show that prior evidence of social contagion gained from the Medical Innovation study by Coleman et al. (1966) is an artifact arising from omitting the effect of marketing efforts. ${ }^{4}$ Medical Innovation is a study on the role of social networks in the diffusion of the broad-spectrum

\footnotetext{
${ }^{3}$ Granovetter (1978) warned of cases in which individuals appear to react to one another when they are actually responding to a common, external influence. In support, he provided this memorable quote from Weber ([1921] 1968, p. 23): "Thus, if at the beginning of a shower a number of people on the street put up their umbrellas at the same time, this would not ordinarily be a case of action mutually oriented to that of each other, but rather of all reacting in the same way to the like need of protection from the rain."

${ }^{4}$ In this article, we use the term "marketing efforts" to denote the range of activities that a supplier engages in to further the sales of its product. Apart from developing appealing products, marketing efforts include impersonal marketing communication (advertising and direct mail), personal selling (termed "detailing" in the pharmaceutical industry), obtaining free publicity, and managing pricing and distribution (e.g., Bagozzi 1986; van Waterschoot and Van den Bulte 1992).
} 
American Journal of Sociology

antibiotic tetracycline among physicians in four communities in the American Midwest during the mid-1950s. It is often credited with documenting innovation diffusion as a social process in which adoption is driven by social contagion (Rogers 1995). The study has more than just historical interest, though. Its data on the diffusion of tetracycline have become "a strategic research site for testing new propositions of how social structure drives contagion" (Burt 1987, p. 1301) and for assessing the performance of new modeling techniques (Marsden and Podolny 1990; Strang and Tuma 1993; Valente 1996). While recent reanalyses of the data have found social contagion effects to be rather small (Burt 1987; Burt and Janicik 1996), sensitive to model specification (Strang and Tuma 1993), or even insignificant (Marsden and Podolny 1990), these reanalyses were primarily designed to investigate which social contagion mechanism was operating (information sharing among cohesive actors vs. competitive mimesis among positionally equivalent actors) or to assess the performance of new models in capturing contagion patterns in the data. With such objectives, previous reanalyses assumed that contagion was truly at work. Therefore, none started with a detailed account of how the market for the new drug operated nor included variables capturing time-dependent nonnetwork mechanisms.

We present our argument in two steps. We first describe the medical community's understanding of antibiotics and sources of drug information at the time the data were originally collected. From this description, we conclude that social contagion is unlikely to have been a key driver in physicians' decision to adopt, but that the pharmaceutical companies' marketing efforts may have played a considerable role. Next, we test this conjecture empirically by applying hazard models to the Medical Innovation data set, which we have supplemented with new data on advertising. Our results indicate that previous evidence of social contagion was spurious. Given the significance of Medical Innovation in the diffusion literature, our findings underscore the risk of confounds in research on social contagion in innovation diffusion.

\section{SITUATIONAL ANALYSIS OF TETRACYCLINE AND THE MEDICAL COMMUNITY}

Medical Innovation is a study of the adoption of tetracycline, a broadspectrum antibiotic, by 125 physicians in four small cities in Illinois. At the time that Lederle launched the first tetracycline-based product in November 1953, three other broad-spectrum antibiotics were already on the market. Lederle had introduced chlortetracycline in 1948, Parke-Davis had introduced chloramphenicol in 1949, and Pfizer had introduced oxy- 


\section{Contagion versus Marketing}

tetracycline in 1950. To better understand the situation physicians found themselves in when deciding whether or not to adopt the new drug, we analyze the product's characteristics, the way it was commercialized, and the kind of sources of information and influence physicians in the 1950s typically used.

\section{Product Characteristics}

The diffusion literature suggests that an innovation's rate of adoption is affected by potential adopters' perceptions of five critical characteristics: complexity, compatibility with existing values, trialability, observability of results, and relative advantage over alternatives (Rogers 1995). Tetracycline had product characteristics typically associated with rapid diffusion.

Low complexity.-Tetracycline was chemically similar to two existing and successful antibiotics, as evidenced by their generic names. Though a new compound, tetracycline "was merely the newest in an already established family of drugs," and an "undramatic pharmaceutical innovation" (Coleman et al. 1966, pp. 17, 36).

Compatibility.-Physicians were favorably disposed toward the pharmaceutical industry, its new products, and efforts to market them (Ben Gaffin 1959; Caplow and Raymond 1954). Enthusiasm was particularly strong for antibiotics (Peterson et al. 1956). ${ }^{5}$

Trialability and observability of results.-Broad-spectrum antibiotics were generally used in the treatment of acute, rather than chronic, conditions. Because of the short time between treatment and outcome, a physician could easily and quickly determine drug efficacy in any particular case and adjust the therapy if necessary (Coleman et al. 1966, p. 17).

Relative advantage.-Tetracycline produced fewer side effects than the other three broad-spectrum antibiotics (Pearson 1969). Tolerance and side effects had become a very important issue by the time tetracycline was launched. In the summer of 1952, the side effects of chloramphenicol,

${ }^{5}$ Peterson et al. (1956) intensively studied 88 general practitioners in North Carolina, each over a period of three to three-and-a-half days. They often observed the physicians immediately prepare an injection of penicillin upon learning that the patient had a fever. This decision was frequently reached before the patient had been examined. Two-thirds of the physicians gave antibiotics to all patients suffering from respiratory infections without attempting to determine whether the infection was viral or bacterial (antibiotics are ineffective against viral infections). Also, "it was apparent from observation and statements from physicians that their practices in regard to medications and therapy are influenced significantly by the information and products supplied by the drug salesman" (p. 103). 
American Journal of Sociology

marketed under the brand name Chloromycetin, received wide press coverage. A June 28 editorial of the Journal of the American Medical Association (JAMA) called doctors' attention to reports on Chloromycetin's side effects, and on July 3 the American Medical Association issued a press release-"AMA Warns Doctors on Chloromycetin Therapy"- that received wide coverage in the popular press. Finally, the FDA even withdrew the drug's certificate, organized its own field survey, and turned its reports over to the National Research Council for review. On August 14, the drug was allowed back on the market, although Parke-Davis was ordered to print prominently on its labels the dangers inherent in its use (Fortune 1953; Pearson 1969). As a result of these problems, Chloromycetin's share of the broad-spectrum antibiotics market declined to $5 \%$ in October 1952, down from 38\% four months earlier. In September 1953, two months before Lederle's launch of tetracycline, Chloromycetin's share was still at only 10\% (Fortune 1953). Thus, tetracycline had a competitive advantage on a product dimension that was especially salient at the time of its launch.

In sum, tetracycline's characteristics present strong reasons to expect rapid diffusion. Also, there is little reason to expect social contagion to have been important. Since there was little ambiguity or perceived risk in prescribing tetracycline, information from previous adopters should not have affected physicians' evaluation of the drug in a major way. Since tetracycline was merely the newest member of an already established family of drugs and an undramatic innovation, it is also questionable that adopting it would have markedly enhanced physicians' status among their peers.

\section{Commercial Context}

An analysis of the potential adopter's situation should also include a view of the supply side. In this section, we document characteristics that have been found to be associated with rapid diffusion (e.g., Bauer 1961; Hahn et al. 1994): the intensity of competition among suppliers, the reputation of suppliers among potential adopters, and the marketing efforts of suppliers.

In contrast to other broad-spectrum antibiotics, tetracycline did not enjoy exclusive patent protection. After a tumultuous episode of litigation, the parties involved worked out a complex patent sharing and licensing agreement, giving Lederle, Pfizer, and Bristol the right to manufacture and sell the drug and allowing Squibb and Upjohn to sell the drug under a supply contract with Bristol (FTC 1958, pp. 245-57). These five firms accounted for more than half of all the antibiotics sold in the United 


\section{Contagion versus Marketing}

States in 1950, and all had a good reputation within the medical community (FTC 1958).

Lederle, the first company to launch a tetracycline formulation, deployed a very aggressive marketing program for its tetracycline brand Achromycin. Coleman et al. (1966, pp. 44, 181) mention the "blanket exposure of all doctors to the detail man [i.e., pharmaceutical representative visiting physicians]." Lederle's direct mail budget for tetracycline permitted 105 mailings, an average of two per week, to every physician in the United States during its first year of commercialization. Medical journal advertising for the first 12 months consisted of 26 insertions in $J A M A$ and monthly insertions in the highly circulated Modern Medicine and Medical Economics, as well as in all state journals, 116 county journals, and most specialty journals (FTC 1958). Tetracycline also received wide positive coverage in the professional media (Ben Gaffin and Associates [1956] 1961b). As a detail man remarked, "Lederle was interested in bombarding physicians with the Achromycin name and we did just that and got the name across. We swamped them with Achromycin" (FTC 1958, p. 130). Pfizer was much less aggressive in pushing tetracycline, fearing that strongly promoting its own brand of tetracycline, Tetracyn, would undercut its sales of oxytetracycline. Only in January 1955, possibly alarmed by the tremendous success of Lederle's Achromycin, did Pfizer start to market Tetracyn more aggressively (Mines 1978). We have no detailed information on how aggressive the other three players marketed their own tetracycline brand. They did not face the same fear of product cannibalization as Pfizer did, and they appear to have been more aggressive than Pfizer, though they lacked the resources to be as aggressive as Lederle (Pearson 1969).

Tetracycline was not only extensively promoted, but also aggressively priced. Although the product was superior to other broad-spectrum antibiotics, its price to consumers was the same as that of the three other types of broad-spectrum antibiotics (FTC 1958). To the extent that physicians took price into consideration in their prescription behavior, tetracycline pricing would have favored rapid adoption.

In sum, tetracycline was marketed by a small group of companies enjoying a solid reputation. The first company to enter the market, Lederle, deployed a very intensive marketing campaign. The product also enjoyed a large amount of free publicity. Although superior in therapeutic effects, the product did not carry a price premium. Such a market environment is conducive to rapid initial diffusion (Bauer 1961; Hahn et al. 1994), irrespective of social influence among physicians.

Exposed to such intensive marketing efforts, physicians did not need word of mouth from their colleagues to become aware of the product's existence and purported benefits. Coleman et al. (1966, pp. 13-14) argued 


\section{American Journal of Sociology}

that the physicians' problem was not too little but too much information. Social contagion, then, need not have operated by creating awareness but by physicians' turning to their colleagues as a way to cope with information overload. Physicians who already had adopted may then have led others to evaluate the new drug positively. However, such a simplifying cognitive strategy is necessary only if actors experience ambiguity or uncertainty, a condition that appears to have been unlikely. While there was indeed a deluge of information, it all pointed in the same direction: in favor of adopting tetracycline.

\section{Physicians' Sources of Information}

A number of studies provide insight into the relative importance of the physicians' various sources of information about new drugs around the time of the tetracycline study. Many of these studies were conducted in the Midwest or in relatively small cities and can thus be expected to be representative of the four Illinois towns studied in Medical Innovation.

A 1952 survey of midwestern physicians reported that they found detail men, direct mail, journal articles, and journal advertising to be much more important sources of information than their colleagues (Caplow and Raymond 1954). Menzel and Katz (1955) conducted the pilot study for Medical Innovation in a New England city of comparable size to the four cities in the main study. They also found that physicians rated colleagues as less important than detail men, articles in journals, and direct mail. A study of the diffusion of Lederle's Achromycin brand in another small midwestern city found similar results (Ben Gaffin and Associates 1961b), as did Ferber and Wales (1958), using a sample of Chicago physicians, and Winick (1961) in a study of an ethical drug introduced in 1957. National scale studies by the National Opinion Research Center (Hawkins 1959), Ben Gaffin and Associates (1959), and Harris (1966) reported similar findings as well. All these studies indicate that physicians in the 1950s typically did not report peer influence as an important information source for new pharmaceuticals but noted commercial communication efforts and medical journals to be more important and more valuable.

\section{Conclusion from the Situational Analysis}

Overall, tetracycline's product characteristics, the way it was marketed, and the sources of information physicians typically used for adoption decisions do not paint a case for strong contagion effects. Table 1, reconstructed from original reports on the Medical Innovation study, shows that physicians considered colleagues to be a source of information and influence, but not a very important one. 
Contagion versus Marketing

TABLE 1

Doctors' Reported Sources When Adopting Tetracycline

\begin{tabular}{|c|c|c|c|c|c|}
\hline \multirow[b]{3}{*}{ SOURCE OF INFLUENCE } & \multicolumn{5}{|c|}{$\%$ Physicians } \\
\hline & \multicolumn{2}{|c|}{$\begin{array}{l}\text { Crediting Source } \\
\text { with* }\end{array}$} & \multicolumn{3}{|c|}{$\begin{array}{l}\text { Mentioning Source of } \\
\text { Information } \text { as }^{\dagger}\end{array}$} \\
\hline & $\begin{array}{l}\text { Original } \\
\text { Influence }\end{array}$ & $\begin{array}{l}\text { Most } \\
\text { Influence }\end{array}$ & First & Intermediate & Final \\
\hline Detail men ................ & 57 & 38 & 52 & 27 & 5 \\
\hline Journal articles.....$\ldots \ldots$ & 7 & 23 & 6 & 21 & 21 \\
\hline Direct mail & 18 & 8 & 22 & 16 & 14 \\
\hline Drug house periodicals ... & 4 & 5 & 3 & 11 & 21 \\
\hline Colleagues $\ldots \ldots \ldots \ldots \ldots$. & 7 & 20 & 10 & 15 & 28 \\
\hline Meetings $\ldots \ldots \ldots \ldots \ldots \ldots$ & 3 & $\ldots$ & 3 & 4 & 8 \\
\hline All other media $\ldots . . . \ldots$. & 4 & 6 & 3 & 7 & 3 \\
\hline
\end{tabular}

* Based on Katz (1961, p. 77). A cross-check against the Medical Innovation network data set prepared by Burt (1986) indicates that the base for these percentages are the 141 physicians (out of a total of 216 interviewed after the 12 exploratory interviews) whose most recent adoption was tetracycline.

$\uparrow$ Based on Coleman et al. (1966, p. 59). Data were available for 87 adopters, who generated 131 mentions of sources intermediate to first and last source. Thus, the base for the percentages in the first and third column is 87 ; for those in the middle the base is 131 .

One might raise the following questions: If advertising and detailing were indeed as important as our situational analysis suggests, would Coleman et al. not have taken these factors into account? Does the fact that they did not include these factors in their analysis not reduce the face validity of our own conclusions? We do not believe so. In appendix A, we document that the way Medical Innovation came about may have led its authors away from looking into the effects of detailing and journal advertising. Appendix A also presents a reminiscence by Coleman indicating that he and his fellow authors may not have been very familiar with the institutional details of their research site.

\section{STATISTICAL ANALYSIS INCORPORATING MARKETING EFFORT}

Our description of the medical community's understanding of tetracycline and of physicians' sources of information indicates that marketing efforts by the drug manufacturers, and especially Lederle, may have been key drivers of the diffusion process. Earlier analyses, however, have ignored this factor, and their results may therefore have been based on a confound. We investigate this possibility empirically below.

\section{Substantive Assumptions}

We assume that to adopt, physicians must both be aware of the innovation and evaluate it positively. Using insights from social network threshold 


\section{American Journal of Sociology}

modeling, we assume that awareness and utility thresholds may vary as a function of physician characteristics (Erikson 1998; Granovetter 1978; Hedström 1994; Valente 1996). Awareness can be driven by marketing efforts (such as sales calls by detail men and advertising), free publicity in medical journals, and exposure to peers who have adopted previously and with whom one shares information on medical practice. Marketing efforts, free publicity, and social contagion can also affect evaluation.

We assume that social contagion stems from exposure to alters who have already adopted and that it operates over personal relationships. This social influence may take the form of information transfer, making one aware of the existence of the drug or improving one's evaluation of the drug's therapeutic merits. Social influence may also consist of social normative pressure: to maintain attitudinal balance, one may feel compelled to adopt once many of one's direct peers have done so. Our data will not allow us to distinguish between these two "social cohesion" processes, but we will distinguish them from social influence operating as competitive mimicry of structurally equivalent colleagues who a physician feels compelled to imitate for fear of losing status in the community (cf. Burt 1987). Our inability to operationalize uniquely each social contagion mechanism is not important, as our purpose is not to distinguish between alternative theories positing each type of process, but rather to distinguish between social contagion and contextual effects, specifically marketing efforts measured through advertising volume.

\section{Model Specification}

We use discrete-time hazard modeling to relate explanatory variables to adoption behavior (Allison 1982). Operationalizing social network exposure through lagged endogenous autocorrelation terms (cf. Hedström 1994; Strang 1991), we represent the hazard of adoption of physician $i$ at time $t$ as

$$
\operatorname{prob}\left(y_{i, t}=1 \mid y_{i, t-1}=0\right)=F\left(\boldsymbol{\alpha}^{\prime} \mathbf{x}_{i t}+\beta \Sigma_{j} w_{i j} y_{j, t-1}\right),
$$

where $y_{i, t}=1$ if $i$ has adopted by time $t$, and $y_{i, t}=0$ otherwise; $F$ is a cumulative distribution function; $\mathbf{x}_{i t}$ is a vector of variables affecting $i$ 's decision to adopt, irrespective of any influence from colleagues (the vector includes an intercept, a summer dummy, physician characteristics, and two advertising variables, which are described below); $w_{i j}$ is social exposure of physician $i$ to physician $j$ (described below); $\alpha, \beta$ are a vector of parameters and a parameter to be estimated, respectively. Discretetime hazard models are appropriate here because several adoptions occur in each observation period. Van den Bulte and Lilien (1999) show that these statistical models also have the theoretically attractive property that 


\section{Contagion versus Marketing}

they can be derived from both random utility theory and random social network threshold models.

Data

Coleman et al. (1966) provide a detailed description of the population, the sample, and data collection procedures. Burt (1986) placed the portion of the original data set that we use in the public domain. Since the data are publicly available, we limit our discussion to the variables we used or constructed for our own analysis.

Physician characteristics. - We included five covariates to account for heterogeneity in physicians' tendency to adopt early. Professional age measures (on a 1-6 scale) how long ago the physician graduated from medical school. We included both a linear and a quadratic term to account for a possible inverse $\mathrm{U}$-shaped relationship between professional age and inclination toward adoption: compared to midcareer physicians, older physicians may be more conservative and very inexperienced physicians more averse to risk. We mean-centered age to reduce collinearity. We used the number of journals a physician receives or subscribes to as a measure of media exposure. Journals included both newsletters sent by pharmaceutical companies and scientific and professional publications. We used the logarithm to reflect decreasing returns to scale. We expected physicians having a chief or honorary position in their hospital, captured as a dummy variable, to be less involved in actual medical practice than were active or regular staff, and hence more likely to adopt later. We also included an attitudinal measure, scientific orientation, coded as " 1 " if the physician agreed with the statement that it is more important for a physician to "keep himself informed of new scientific developments [than to] devote more time to his patients," and " 0 " otherwise.

We also estimated models including the number of nominations a physician received as advisor or as discussant as measures of status. Although sociometric status figures prominently in the analysis by Coleman and his associates, it did not contribute significantly to model fit, nor did it change the coefficients of the contagion variables once we controlled for the number of journals received. Burt (1987), Marsden and Podolny (1990), and Strang and Tuma (1993) reported similar findings. It appears that opinion leaders adopted early as a result of their cosmopolitan perspective and media habits rather than due to pressure to maintain their status among their colleagues. We report results only for models excluding sociometric status variables.

Seasonal effects.-We included a seasonal dummy variable for the summer months of July and August. We expected fewer adoptions of a new antibiotic in these two months because the weather is warmer and schools 


\section{American Journal of Sociology}

are closed, limiting the spread of contagious diseases and in turn the demand for antibiotics (Cliff et al. 1981).

Advertising volume.-The Medical Innovation data do not contain information on the amount of marketing effort targeted toward the physicians whose prescriptions were tracked. We use the number of advertising pages in three leading advertising outlets, Modern Medicine, Medical Economics, and GP, as our measure of marketing effort. These three publications were preferred by pharmaceutical advertisers and were widely read by physicians in the 1950s (Ben Gaffin and Associates [1953] $1961 a, 1961 b$ ). Our attempts to collect data on the number of ads appearing in $J A M A$ were unsuccessful, as librarians removed the advertising supplement before binding the issues for storage.

We distinguish between the marketing efforts by the first entrant, Lederle, and those of the later entrants. We do so for two reasons. First, the first entrant's marketing efforts are often more effective than those of later entrants when the latter do not offer an important therapeutic advantage (Bond and Lean 1977; Hurwitz and Caves 1988; Shankar, Carpenter, and Krishnamurthi 1998). Second, Lederle had a very large sales force and was strongly committed to building a dominant position aggressively while other companies were less well endowed and less aggressive.

We matched the number of advertisements in each issue to the fourweek sampling periods in the data set prepared by Burt (1986). Because the data are monthly observations and because previous research in the pharmaceutical industry documents the presence of sizable spillover effects over time (Berndt et al. 1997; Montgomery and Silk 1972; Rangaswamy and Krishnamurthi 1991), we expected marketing communication effects to span multiple periods. We therefore constructed measures of depreciation-adjusted stock of marketing effort (Berndt et al. 1997; Kalish and Lilien 1986; Rizzo 1999). Let $m_{t}$ be the amount of advertising in month $t$ (in hundreds of pages), and let $\delta$ be the monthly decay rate $(0 \leq \delta \leq 1)$. The stock of marketing effort $M_{t}$ is then defined as

$$
M_{t}=m_{t}+(1-\delta) M_{t-1}=\sum_{\tau=0}^{t}(1-\delta)^{t-\tau} m_{\tau} .
$$

We constructed one such variable for Lederle and one for all other competitors combined. We assumed that the decay parameter $\delta$ (to be estimated) was equal across companies.

We have not been able to locate data on the amount of detailing effort by various companies marketing tetracycline, but we do not believe this to be a problem. Detailing effort and journal advertising are so highly correlated in pharmaceutical markets that either variable can be used to 


\section{Contagion versus Marketing}

represent overall marketing effort (Berndt et al. 1997; Gatignon, Weitz, and Bansal 1990; Lilien, Rao, and Kalish 1981; Rangaswamy and Krishnamurthi 1991; Rizzo 1999).

We do not include interaction effects between marketing effort and the number of journals received. While such interactions would normally provide a sharper test of advertising effects, they would be unlikely to do so in this case because the journal subscription variable does not discriminate between exposure to commercial and scientific content. Nor does it distinguish scientific journals, Lederle's newsletter, and competitors' newsletters from one another. We see no reason why a physician with above-average exposure to the scientific information in medical journals and company-specific newsletters would have been differentially sensitive to advertising or visits by detail men. Nor do we see a reason why the effectiveness of Lederle's advertising would have been boosted among physicians who received many newsletters or were exposed to many journal advertisements, not only from Lederle but also from its competitors having a stake in promoting other broad-spectrum antibiotics. A similar argument applies for the later entrants. Another reason not to expect a significant interaction between journal subscriptions and later entrants' marketing efforts is that the latter's effectiveness is likely to be low overall (Bond and Lean 1977; Hurwitz and Caves 1988; Shankar et al. 1998), resulting in a floor effect precluding the detection of significant interaction effects. ${ }^{6}$

Contagion variables.-We define the social influence that physician $i$ is subject to at time $t$ as a function of whether other physicians ( $j$ ) have adopted previously (indicated by $y_{j, t-1}$ ) and how important each physician $j$ is to $i$ (indicated by the social weight $w_{i j}$ ). The extent of social network exposure $i$ is experiencing can then be expressed as a lagged network autocorrelation variable $\Sigma_{j} w_{i j} y_{j, t-1}$ (e.g., Marsden and Podolny 1990; Strang 1991). The actual social contagion, that is, influence on adoption behavior, is then $\beta \Sigma_{j} w_{i j} y_{j, t-1}$, where $\beta$ is a parameter to be estimated.

Coleman et al. (1966) had 228 physicians interviewed. Each physician was asked to name up to three other physicians with whom he discussed medical practice, and up to three physicians from whom he sought advice about medical practice. However, Coleman et al. had prescription data collected only for general practitioners $(N=125)$ and not for specialists. There are two approaches to this missing data problem. Burt (1987) and

${ }^{6}$ To check these a priori reservations, we performed analyses including interaction terms between number of journals received and marketing stock of both Lederle and the other entrants. As expected, the interaction terms were not significant $(P>0.10)$. The point estimates and significance test of all the other parameters were strikingly similar to those reported below in this article. Detailed results of these additional analyses are not reported here but are available on request from the authors. 
American Journal of Sociology

Marsden and Podolny (1990) assumed that the adoption of tetracycline by specialists affected generalists' decision to adopt; consequently these authors imputed adoption dates for specialists (though they only analyzed the generalists' adoptions). In contrast, Coleman et al. (1966) and Strang and Tuma (1993) assumed that generalists did not take specialists' adoption behavior into account; these authors thus do not consider the latter's missing adoption data when constructing the social influence variables. We used both approaches, as Strang and Tuma (1993) suggested that different assumptions about the effects of specialists on generalists may have caused different reanalyses to find evidence of social contagion or not.

We constructed two types of exposure variables, each assuming a different influence mechanism represented by the $w_{i j}$ weights. The direct ties weights reflect whether $i$ nominated $j$ as an interaction partner for advice or discussions, such that $i$ might have gained information or experienced social normative pressure from $j$. We also constructed weights of structural equivalence indicating whether $i$ might mimic $j$ out of fear of losing out in the competition for status. We operationalized structural equivalence as the proportion of exact matches between two physicians' set of relationships with third parties: thus, the more their portfolio of relationships overlap, the higher the weight they give to one another. Appendix B details how we constructed the network exposure variables $\Sigma_{j} w_{i j} y_{j, t-1}$.

We also used the network exposure variables constructed by Burt (1986): one captures word of mouth operating over direct ties and one captures competition for status between structurally equivalent physicians. Burt incorporated specialists' imputed adoption data in his exposure variables. He also used different operationalizations of the influence weights than we did. Because of imputation problems, Burt could not compute exposure to structurally equivalent colleagues for seven physicians. For one of these seven, Burt was also unable to compute a measure of social cohesion influence. For these few physicians, we substituted our measures of influence through structural equivalence and direct ties for Burt's missing values.

After constructing the variables, we deleted four physicians, due to missing covariates. The data set for estimation contains 17 monthly observations for 121 individuals, 105 of whom had adopted by the last observation period. Table 2 presents descriptive statistics for the data, after excluding postadoption observations irrelevant to explain adoption.

Figure 1 graphs the cumulative proportion of physicians having adopted in each period $\left(=\Sigma_{j} w_{i j} y_{j t}\right.$, assuming perfect social mixing, i.e., $w_{i j}=1 / N$ for all $i$ and $j$ where $N$ is the number of actors) as well as the marketing stock $M_{t}$ of Lederle and the other entrants. The graph shows that the cumulative fraction of adopters, a rough proxy for average net- 
TABLE 2

Descriptive Statistics of Model Variables

\begin{tabular}{|c|c|c|c|c|c|c|c|c|c|c|c|c|c|c|c|c|}
\hline \multirow[b]{2}{*}{ VARIABLE } & \multirow[b]{2}{*}{ MEAN } & \multirow[b]{2}{*}{$\mathrm{SD}$} & \multirow[b]{2}{*}{ MiN } & \multirow[b]{2}{*}{ Max } & \multicolumn{12}{|c|}{ CORRELATIONS } \\
\hline & & & & & 1 & 2 & 3 & 4 & 5 & 6 & 7 & 8 & 9 & 10 & 11 & 12 \\
\hline 1. $y$ (adoption indicator) & .111 & .314 & 0 & 1 & & & & & & & & & & & & \\
\hline 2. Summer .............. & .084 & .278 & 0 & 1 & -.05 & & & & & & & & & & & \\
\hline 3. Age & .000 & 1.706 & -2.54 & 2.46 & -.09 & .05 & & & & & & & & & & \\
\hline 4. $\mathrm{Age}^{2}$ & 2.907 & 2.561 & .21 & 6.48 & -.08 & .05 & .17 & & & & & & & & & \\
\hline 5. Journals $(\log ) \ldots \ldots \ldots \ldots \ldots \ldots$ & 1.484 & .392 & .69 & 2.20 & .10 & -.07 & -.16 & -.03 & & & & & & & & \\
\hline 6. Science & .268 & .443 & 0 & 1 & .12 & -.08 & -.01 & .01 & -.02 & & & & & & & \\
\hline 7. Chief $\ldots \ldots \ldots \ldots \ldots \ldots \ldots \ldots \ldots \ldots \ldots \ldots \ldots \ldots$ & .098 & .298 & 0 & 1 & -.05 & .00 & .31 & .26 & .06 & .29 & & & & & & \\
\hline 8. Direct ties $\ldots \ldots \ldots \ldots \ldots \ldots \ldots \ldots \ldots \ldots$ & .384 & .413 & 0 & 1 & .01 & .25 & .15 & .18 & -.05 & -.14 & .17 & & & & & \\
\hline 9. Structural equivalence $\ldots \ldots \ldots \ldots$ & .379 & .321 & 0 & 1 & .01 & .25 & .13 & .14 & -.22 & -.16 & .05 & .75 & & & & \\
\hline 10. Direct ties (Burt) …............... & .334 & .321 & 0 & 1 & .07 & .18 & .15 & .07 & -.04 & -.14 & .09 & .68 & .70 & & & \\
\hline 11. Structural equivalence (Burt) ... & .451 & .419 & 0 & 1 & .02 & .27 & .18 & .09 & -.15 & -.16 & .15 & .86 & .82 & .72 & & \\
\hline 12. Advertising by Lederle ......... & .155 & .087 & 0 & .24 & .05 & .30 & .13 & .12 & -.17 & -.19 & .05 & .68 & .80 & .69 & .75 & $\ldots$ \\
\hline 13. Advertising by others $\ldots \ldots \ldots \ldots$ & .191 & .224 & 0 & .98 & .03 & .02 & .16 & .12 & -.14 & -.17 & .06 & .57 & .71 & .63 & .60 & .68 \\
\hline
\end{tabular}

Note. - Items 8 and 9 utilize our data; items 10 and 11 utilize data from Burt (1986). 

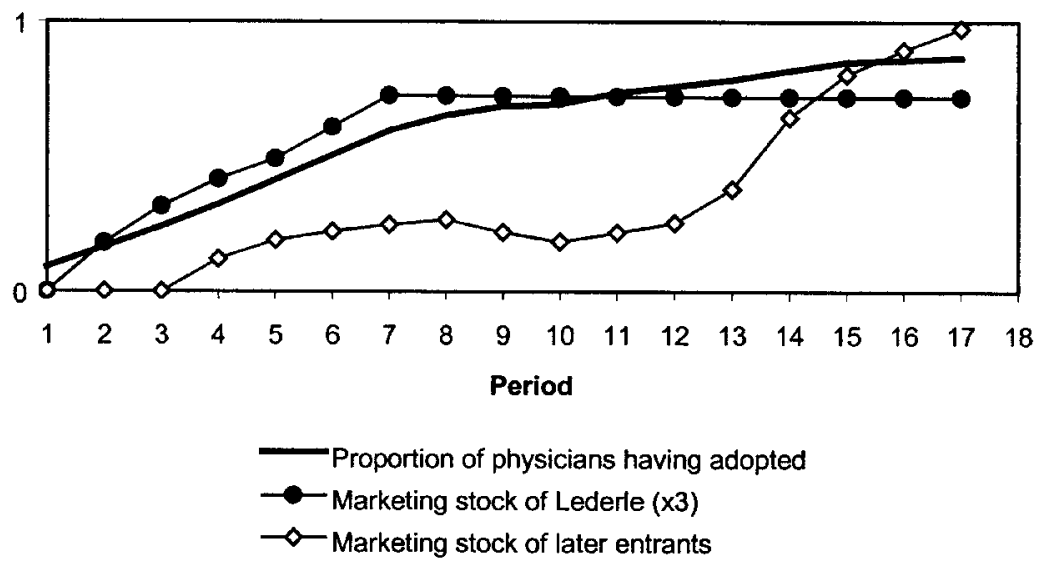

FIG. 1.-Adoptions and marketing stock; marketing stock is defined as the depreciationadjusted cumulative advertising volume (see eq. [2]).

work exposure, closely tracks Lederle's marketing stock, hence suggesting the threat of a confound. Figure 2 graphs the empirical hazard rate, that is, the number of physicians adopting in period $t$ divided by the number of physicians not having adopted prior to period $t$, together with the two marketing stock variables. The hazard rate increases with Lederle's marketing stock between periods 2 and 7 . As Lederle's marketing stock flattens, the hazard begins to behave more erratically. It even drops in periods 9 and 10 (July-August 1954), possibly due to the summer effect. The hazard rate picks ups again between periods 10 and 15, which coincides with increased marketing efforts by later entrants, but the increase is irregular and not sustained after period 15. Figure 2 suggests that marketing efforts, especially by Lederle, may have been associated with adoption.

\section{Estimation and Specification Tests}

We used both logit and probit specifications and estimated our models using maximum likelihood, with one exception. We estimated the marketing effort decay parameter $\delta$ using a grid search (cf. Berndt et al. 1997) in a model that did not feature social network exposure variables. A value of $\delta=0.25$ led to the highest model likelihood. Model fit was not very sensitive to changes in the range between 0.15 and 0.30 . In subsequent analyses of models featuring both marketing effort and social network exposure, we kept $\delta$ fixed at 0.25 .

We checked for unobserved heterogeneity in both probit and logit mod- 


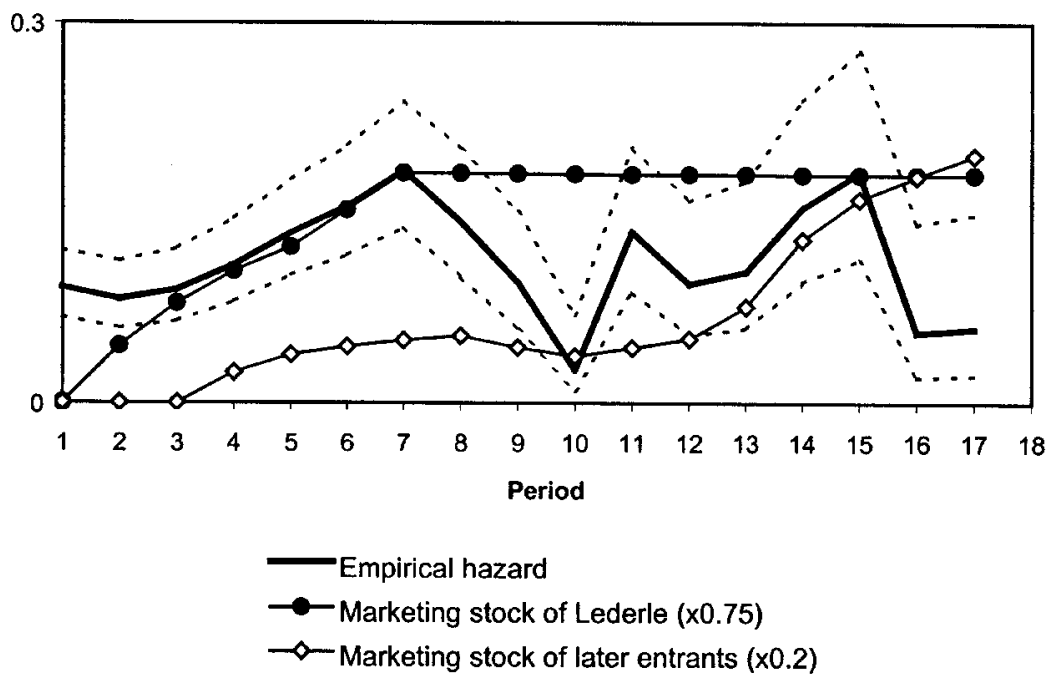

FIG. 2.-Empirical hazard rate and marketing stock. The broken lines around the empirical hazard rate indicate the SE interval $(+/-1)$. We computed SEs using a logit hazard model. The interval is not symmetric because the logit model is linear in the log odds of the hazard rate, not in the hazard rate itself.

els. In the probit models, we estimated a normal mixture while allowing the base hazard to vary freely every three months (cf. Han and Hausman 1990). In the logit models, we used the score tests developed by Hamerle (1990) and Commenges et al. (1994). None of these tests suggested the presence of significant unobserved heterogeneity $(P>0.10)$. We present the results for the logit specification only and omit the test statistics for unobserved heterogeneity.

Results

Table 3 reports the results for each of the four social network exposure variables: two for exposure through direct ties (both our own and Burt's measure) and two for exposure through structural equivalence (again our own and Burt's measure). The four first columns (1a-4a) report the logit coefficients in models without marketing effort. Social contagion is significant in all four cases. Exponentiating the social contagion coefficients reported in table 3 indicates that the odds of adoption by someone with maximum exposure was two to three times the odds of adoption by someone without any social network exposure. Also, the coefficients of all physician characteristics except for age have the expected sign and are significant at $90 \%$ confidence or higher. Age does not have the expected 
TABLE 3

Empirical Proof That Marketing Effort, Not Social Contagion, Is Associated with Adoption Behavior

\begin{tabular}{|c|c|c|c|c|c|c|c|c|c|}
\hline & \multicolumn{4}{|c|}{ Without Marketing EfFort } & \multicolumn{5}{|c|}{ With Marketing EfFort } \\
\hline & $1 \mathrm{a}$ & $2 \mathrm{a}$ & $3 \mathrm{a}$ & $4 \mathrm{a}$ & $1 b$ & $2 \mathrm{~b}$ & $3 \mathrm{~b}$ & $4 \mathrm{~b}$ & 5 \\
\hline \multicolumn{10}{|l|}{ Common tendencies: } \\
\hline Intercept $\ldots \ldots \ldots \ldots$ & $-3.48 * * * *$ & $-3.69 * * * *$ & $-3.82 * * * *$ & $-3.78 * * * *$ & $-4.46 * * * *$ & $-4.31 * * * *$ & $-4.14 * * * *$ & $-4.14 * * * *$ & $-4.42 * * * *$ \\
\hline Summer $\ldots \ldots \ldots \ldots$. & -.61 & -.63 & -.65 & -.69 & -.77 & -.82 & -.76 & -.80 & -.79 \\
\hline \multicolumn{10}{|l|}{ Intrinsic tendencies: } \\
\hline Professional age & -.12 & $-.14 *$ & -.12 & $-.13^{*}$ & $-.13^{*}$ & $-.14^{*}$ & $-.13 *$ & $-.13 *$ & $-.13^{*}$ \\
\hline Professional age $^{2}$ & $-.09 * *$ & $-.09 *$ & $-.10 * *$ & $-.09 *$ & $-.10 * *$ & $-.10 * *$ & $-.10 * *$ & $-.10 * *$ & $-.10 * *$ \\
\hline Chief or honorary position ... & $-.92 *$ & $-.94 *$ & $-.86^{*}$ & $-1.02 * *$ & $-.95 *$ & $-1.00 * *$ & $-.98 * *$ & $-.98 * *$ & $-.97 * *$ \\
\hline$N$ of journals $(\log ) \ldots \ldots \ldots \ldots$ & $.76^{* * * *}$ & $.77 * * *$ & $.91 * * *$ & $.87 * * *$ & $.96 * * * *$ & $.90 * * *$ & $.92 * * *$ & $.95 * * *$ & $.95 * * *$ \\
\hline Scientific orientation & $.97 * * * *$ & $.99 * * * *$ & $.97 * * * *$ & $1.01 * * * *$ & $1.11^{* * * * *}$ & $1.10 * * * *$ & $1.13 * * * *$ & $1.12 * * * *$ & $1.12 * * * *$ \\
\hline Social contagion $\ldots \ldots \ldots \ldots \ldots$ & $.64^{*}$ & $1.18 * * * *$ & $.98 * * *$ & $.81 * * *$ & -.16 & 0.53 & -.44 & .03 & \\
\hline \multicolumn{10}{|l|}{ Marketing effort: } \\
\hline Lederle $\ldots \ldots \ldots \ldots \ldots \ldots \ldots \ldots$ & & & & & $5.61 * * *$ & $4.10^{*}$ & $6.11^{* * * *}$ & $5.13 * *$ & $5.22 * * *$ \\
\hline Others $\ldots \ldots \ldots \ldots \ldots \ldots \ldots$ & & & & & .29 & .02 & .44 & .22 & .23 \\
\hline \multicolumn{10}{|l|}{ Fit: } \\
\hline$-2 \log$ likelihood & 619.2 & 611.5 & 617.1 & 615.8 & 608.0 & 606.8 & 607.6 & 608.2 & 608.2 \\
\hline
\end{tabular}

This content downloaded from 165.123.034.086 on March 19, 2018 14:24:00 PM 


\section{Contagion versus Marketing}

positive sign, suggesting that younger physicians did not delay adoption. The summer dummy variable has the expected negative sign, but is not or is only marginally significant.

The next four columns (1b-4b) report the results for models incorporating marketing efforts. Adding the marketing variables improves model fit substantially in all four cases. The coefficients of the physician characteristics barely change, but the social contagion effects are now all insignificant. As expected from our situational analysis, marketing efforts by Lederle affect adoption more than peer influence or marketing efforts by later entrants, neither of which show a significant effect. Finally, a model with marketing effort but without social network exposure fits about equally well as models with both types of variables (col. 5). Overall, the results indicate that Lederle's marketing efforts, not social contagion, was the dominant driver increasing physicians' hazard of adoption over time.

Discussion of the Statistical Analysis

Though we believe that our description of the physicians' situation at the time the data were collected is accurate and that our statistical analysis supports its predictions, the latter involves both modeling compromises and data restrictions. First, we limited our analysis to interpersonal influence associated with others' past behavior and did not consider others' contemporaneous or anticipated future actions. By ignoring contemporaneous actions, we fail to capture possible joint decision making among physicians. By ignoring how physicians may have anticipated adoptions of their peers and how this in turn may have led them to adopt preemptively to maintain their status within their community, we may not have captured competitive contagion fully. Even though our descriptive analysis suggests contemporaneous social contagion and prospective behavior were unlikely to be important for tetracycline, we did not assess these effects in the statistical analysis. There are both statistical (Besag 1975) and theoretical problems (Coleman 1990) that need to be resolved before considering empirically analyzing the effects of contemporaneous and anticipated actions in complex, nonrandom network structures. ${ }^{7}$

Second, our analysis is constrained by the lack of richness in the data

\footnotetext{
${ }^{7}$ Strang and Tuma (1993) do model contemporaneous contagion. Their estimation procedure, however, does not account for the interdependence among observations explicitly present once one allows for contemporaneous contagion. Traditional likelihood functions for binary dependent variable models, which include discrete-time hazard models used in the present study, do not account for this endogeneity. Including a contemporaneous network exposure variable, $\Sigma_{j} w_{i, j} y_{j t}$, would lead to invalid results (Besag 1975).
} 
American Journal of Sociology

about what gets communicated through the network. We assume that social interaction informs potential adopters only about others' adoption, not their expected or achieved utility, attitudes, or other evaluations. This is defensible when actors do not discern internal states or outcomes of others. Sometimes, however, outcomes are actually communicated by adopters (e.g., satisfaction) or can be observed (e.g., market share gains or increased fundraising by organizations that implement a new technology). Researchers having such data available can modify the model quite easily by substituting the relevant variable (say, $q_{j, t}$ ) for the $y_{j, t-1}$ indicator and compute network exposure as $\Sigma_{j} w_{i j} q_{j, t}$.

Third, our hazard models do not distinguish between two important stages in the adoption process: awareness followed by evaluation that is itself conditional upon awareness (Rogers 1995). Such separation may help gain a better understanding of the differential effects of advertising and social contagion, as the former is believed to operate mainly early in the decision process and the latter mainly in later stages (Rogers 1995). Modeling the effect of marketing efforts and social contagion without distinguishing between awareness and evaluation might produce misleading results when marketing efforts are quite important in creating awareness and when social contagion is moderately—though still sizably-important in persuading actors to adopt the innovation. When both explanatory variables are forced into a single-stage model, the weaker social contagion effect may be washed out by the marketing effort, erroneously suggesting that social contagion was not at work.

These three caveats mean that both our analysis and those that preceded it may not have been able to identify very subtle social contagion processes affecting the diffusion of tetracycline. Yet, the caveats apply to our own analysis as well as earlier ones and hence do not affect the main implication of our statistical analysis: prior evidence of social contagion in the Medical Innovation data was based on confounding the contextual effect of Lederle's aggressive marketing efforts with social contagion.

Our results about the absence of network effects once one controls for advertising clearly contradict the received view of strong network effects in Medical Innovation (Rogers 1995). At the same time, they also explain the "weak" results obtained by Marsden and Podolny (1990) and Strang and Tuma (1993). Marsden and Podolny estimated a Cox proportional hazard model, which is very similar to a discrete-time logit hazard model with a dummy variable for each time period. These dummies capture all cross-temporal variation in the mean adoption hazard and leave only variance within particular time periods to be explained by network exposure. Strang and Tuma incorporate lagged penetration as a covariate, besides lagged network terms. Lagged penetration assumes that any physician interacts with any other physician (i.e., a constant $w_{i j}$ for all $i$ and 


\section{Contagion versus Marketing}

j), ignoring network structure but capturing the cross-temporal variation in average network exposure. Similarly, our marketing variables vary over time but not across physicians. Hence, all three studies show that differences in adoption across physicians within any particular time period are not statistically significantly associated with differences in lagged social network exposure. Our study, however, is the only one to provide an explanation for this finding grounded in a detailed situational analysis.

\section{CONCLUSION}

Based on a situational analysis of the medical community's understanding of tetracycline in the mid-1950s and on a new statistical analysis, we conclude that Medical Innovation (Coleman et al. 1966) and several subsequent studies that analyze the diffusion of tetracycline have confounded social contagion with marketing effects. Our analysis of the drug's characteristics, the way it was marketed, and the typical sources of information within the medical community, suggest that it is unlikely that social contagion processes were important in physicians' decision to adopt, but that aggressive marketing efforts by Lederle may have had a significant impact. A new statistical analysis of the Medical Innovation data set, supplemented with newly collected data on advertising volume (a measure of marketing effort), shows that contagion effects disappear once we control for marketing effort. Hence, we conclude that the data do not document that diffusion was driven by contagion operating over social networks and that earlier analyses confounded social contagion with the effect of marketing effort.

The danger of confounding common contextual effects with social contagion has been repeatedly discussed in the literature. Yet, given the prominence of the original Medical Innovation study and subsequent reanalyses of the data (esp. Burt 1987) in the diffusion and social network literatures, our results are particularly noteworthy: they underscore, more compellingly than general methodological admonitions, that the danger of confounds when studying the role of social contagion in innovation diffusion must not be taken lightly.

\section{APPENDIX A}

Medical Innovation's Silence Does Not Mean Marketing Efforts Were Irrelevant

The authors of Medical Innovation did not pay much attention to marketing factors in their analysis. This oversight does not reduce the face validity of the conculsions of our situational analysis: Medical Innova- 
American Journal of Sociology

tion's genesis may have led its authors away from looking into the effects of detailing and journal advertising, and the authors may not have been very familiar with all the institutional details of their research site.

The genesis of the original study.-Medical Innovation started off as an advertising effectiveness study for Pfizer, one of the sponsors of Paul Lazarsfeld's Bureau of Applied Social Research at Columbia University. As reported by a former affiliate to the bureau, Pfizer "wanted to find out whether or not it should continue to advertise a new drug in the Journal of the American Medical Association" (Glock 1979, p. 27). Typical of the scholarly entrepreneurship with which Lazarsfeld funded his institute, this rather humdrum marketing question was converted into a sociological study of scholarly interest showing very little surface traces of its mercantile origins (Rogers 1994). It is important to note that, in those days, Pfizer did not place ads in the regular advertising section in $J A M A$, but had its own newsletter, Spectrum (that contained both ads and articles), inserted in each issue of $J A M A$. This, we believe, explains why the study includes multiple questions about specific newsletters and about JAMA but none about regular journal advertising or other medical journals mentioned by name (the questionnaire is reprinted in Coleman et al. 1966, pp. 195-205). The genesis of Medical Innovation as a study on the effectiveness of drug house newsletters redefined into a diffusion study also explains the rather small amount of attention given to detailing as a source of influence.

Familiarity with the research setting.-Consider the following 1993 reminiscence by James Coleman of the Medical Innovation project:

I never saw the communities. It [Medical Innovation] was one of those research projects that happens while you are busy with more important projects. I designed the research with Herb [Menzel] and Elihu [Katz]. Herb and Elihu reviewed the literature on medical innovation. A team of interviewers came out to Illinois from the Bureau to talk to the doctors, and Sidney Spivik searched the prescription records. The questionnaires went back to Columbia to be keypunched, a set of cards were sent to me for analysis, and the research report was published in Sociometry [1957]. (As cited in Burt 1997; square brackets added by Burt)

This recollection indicates that neither Coleman nor his two coauthors had firsthand knowledge of medical practice in the four Illinois communities. Hence, the fact that Medical Innovation does not emphasize the role of marketing efforts in the diffusion of tetracycline cannot be used to infer that those efforts were unimportant. 
Contagion versus Marketing

\section{APPENDIX B}

Procedures Used to Create Social Influence Weights

Our analysis uses both discussion and advice relationships. Using the network data of all 228 physicians, we constructed the social weight matrices for each of the four cities separately in a series of steps.

Step 1.-First, we created adjacency matrices with element $a_{i j}=1$ if $i$ mentions $j$; 0 otherwise. We created two such adjacency matrices for each city: one for discussion ties and one for advice ties.

Step 2.- Since being discussion partners is a naturally reciprocal relationship, we symmetrized the discussion adjacency matrix (Alba and Kadushin 1976).

Step 3.-We constructed a pooled adjacency matrix by adding the symmetrized discussion matrix and the advice matrix, treating discussion and advice as indicators of a common underlying variable "interacting with." We also performed analyses (not reported here) keeping discussion and advice separate. This separation did not affect the results.

Step 4.-We constructed two different weight matrices to account for various network contagion mechanisms. Direct tie matrices are identical to the adjacency matrices. We computed structural equivalence weights as the proportion of exact matches between two physicians' set of relationships with third parties. A valid match required that the physicians had at least one common third party, which implies that actors without any common third party did not put any weight on each other's actions.

Step 5.- We deleted all rows and columns referring to physicians who were not among the 125 included in the prescription sample.

Step 6.-We put all diagonals to zero and normalized all rows such that (1) $w_{i i}=0$, and (2) $\Sigma_{j} w_{i j}=1$, if and only if $w_{i j} \neq 0$ for some $j$, and $\Sigma_{j} w_{i j}=0$ otherwise. This row normalization implies that physicians are sensitive to the proportion rather than the number of relevant others who have adopted, and it ensures that each network exposure variable is bounded between zero and one.

After performing these six steps, actor $i$ 's social network exposure at time $t$ can be computed as $\Sigma_{j} w_{i j} y_{j, t-1}$.

\section{REFERENCES}

Alba, Richard D., and Charles Kadushin. 1976. "The Introduction of Social Circles: A New Measure of Social Proximity in Networks." Sociological Methods and Research 5:77-102.

Allison, Paul D. 1982. "Discrete-Time Methods for the Analysis of Event Histories." Pp. 61-98 in Sociological Methodology, edited by Samuel Leinhardt. San Francisco: Jossey-Bass.

Bagozzi, Richard P. 1986. Principles of Marketing Management. Chicago: Science Research Associates. 


\section{American Journal of Sociology}

Bandura, Albert. 1986. Social Foundations of Thought and Action: A Social Cognitive Theory. Englewood Cliffs, N.J.: Prentice-Hall.

Bauer, Raymond A. 1961. "Risk Handling in Drug Adoption: The Role of Company Preference." Public Opinion Ouarterly 25:546-59.

Bemmaor, Albert C. 1994. "Modeling the Diffusion of New Durable Goods: Word-ofMouth Effect versus Consumer Heterogeneity." Pp. 201-23 in Research Traditions in Marketing, edited by G. Laurent, G. L. Lilien, and B. Pras. Boston: Kluwer Academic Publishers.

Ben Gaffin and Associates. (1953) 1961a. "Report on a Study of Advertising and the American Physician. Part I. The Advertisers' Viewpoint.” Pp. 490-520 in Drug Industry Antitrust Act, Hearings before the Senate Subcommittee on Antitrust and Monopoly of the Committee on the Judiciary. Washington, D.C.: Government Printing Office.

—. (1956) 1961b. "The Fond du Lac Study. A Basic Marketing Study Made for the American Medical Association." Pp. 697-806 in Drug Industry Antitrust Act, Hearings before the Senate Subcommittee on Antitrust and Monopoly of the Committee on the Judiciary. Washington, D.C.: Government Printing Office.

. 1959. Attitudes of U.S. Physicians toward the American Pharmaceutical Industry. Chicago: American Medical Association.

Berndt, Ernst R., Linda T. Bui, David H. Lucking-Reiley, and Glen L. Urban. 1997. "The Roles of Marketing, Product Quality, and Price Competition in the Growth and Composition of the U.S. Antiulcer Drug Industry," Pp. 277-328 in The Economics of New Goods, edited by Timothy F. Bresnahan and Robert J. Gordon. Chicago: University of Chicago Press.

Besag, J. E. 1975. "The Statistical Analysis of Non-Lattice Data." Statistician 24: 179-95.

Bond, Ronald S., and David F. Lean. 1977. "Sales, Promotion, and Product Differentiation in two Prescription Drug Markets.” Economic Report, Federal Trade Commission.

Bonus, Holger. 1973. "Quasi-Engel Curves, Diffusion, and the Ownership of Major Consumer Durables." Journal of Political Economy 81:655-77.

Brown, Lawrence A. 1981. Innovation Diffusion: A New Perspective. New York: Methuen.

Burt, Ronald S. 1986. "The Medical Innovation Network Data." Technical Report no. 3. Columbia University, Center for the Social Sciences.

-1 1987. "Social Contagion and Innovation: Cohesion versus Structural Equivalence." American Journal of Sociology 92:1287-1335.

- 1997. "Neo-Classical Contagion: Recent Developments in the Network Structure of Diffusion." Unpublished note, University of Chicago.

Burt, Ronald S., and Gregory A. Janicik. 1996. "Social Contagion and Social Structure." Pp. 32-49 in Networks in Marketing, edited by Dawn Iacobucci. Thousand Oaks, Calif.: Sage.

Caplow, Theodore, and John J. Raymond. 1954. "Factors Influencing the Selection of Pharmaceutical Products." Journal of Marketing 19 (July): 18-23.

Chatterjee, Rabikar, and Jehoshua Eliashberg. 1990. "The Innovation Diffusion Process in a Heterogeneous Population: A Micromodeling Approach." Management Science 36:1057-79.

Cliff, A. D., P. Haggett, J. K. Ord, and G. R. Versey. 1981. Spatial Diffusion: An Historical Geography of Epidemics in an Island Community. Cambridge: Cambridge University Press.

Coleman, James S. 1990. Foundations of Social Theory. Cambridge, Mass.: Harvard University Press.

Coleman, James S., Elihu Katz, and Herbert Menzel. 1966. Medical Innovation: A Diffusion Study. Indianapolis: Bobbs-Merrill. 


\section{Contagion versus Marketing}

Collier, David, and Richard E. Messick. 1975. "Prerequisites versus Diffusion: Testing Alternative Explanations of Social Security Adoption." American Political Science Review 69:1299-1315.

Commenges, Daniel, Luc Letenneur, Hélène Jacqmin, Thierry Moreau, and JeanFrançois Dartigues. 1994. "Test of Homogeneity of Binary Data with Explanatory Variables." Biometrics 50:613-20.

Davis, Fred D., Richard P. Bagozzi, and Paul R. Warshaw. 1989. "User Acceptance of Computer Technology: A Comparison of Two Theoretical Models." Management Science 35:982-1003.

Delacroix, Jacques, and Hayagreeva Rao. 1994. "Externalities and Ecological Theory: Unbundling Density Dependence." Pp. 255-68 in Evolutionary Dynamics of Organizations, edited by Joel A. C. Baum and Jitendra V. Singh. New York: Oxford University Press.

DiMaggio, Paul J., and Walter W. Powell. 1983. "The Iron Cage Revisited: Institutional Isomorphism and Collective Rationality in Organizational Fields." American Sociological Review 48:147-60.

England, Paula. 1998. Concluding remarks to the Conference on Economic and Organizational Sociology, University of Pennsylvania, December.

Erbring, Lutz, and Alice A. Young. 1979. "Individuals and Social Structure: Contextual Effects as Endogenous Feedback." Sociological Methods and Research 7:396-430.

Erikson, Robert. 1998. "Thresholds and Mechanisms: A Comment on Hedström and Swedberg's Chapter." Pp. 88-93 in Rational Choice Theory and Large-Scale Data Analysis, edited by Hans-Peter Blossfeld and Gerald Prein. Boulder, Colo.: Westview Press.

Ferber, Robert, and Hugh G. Wales. 1958. The Effectiveness of Pharmaceutical Promotion. Urbana: University of Illinois, Bureau of Economic and Business Research.

Fortune. 1953. "Shock Therapy for Parke, Davis." 48 (September): 108-13, 208-14.

FTC (Federal Trade Commission). 1958. Economic Report on Antibiotics Manufacture. Washington, D.C.: Government Printing Office.

Gatignon, Hubert, Barton Weitz, and Pradeep Bansal. 1990. "Brand Introduction Strategies and Competitive Environments." Journal of Marketing Research 27: 390-401.

Glock, Charles Y. 1979. "Organizational Innovation for Social Research and Training." Pp. 23-36 in Qualitative and Quantitative Social Research: Papers in Honor of Paul F. Lazarsfeld, edited by Robert K. Merton, James S. Coleman, and Peter H. Rossi. New York: Free Press.

Granovetter, Mark S. 1978. "Threshold Models of Collective Action.” American Journal of Sociology 83:1420-43.

Hahn, Minhi, Sehoon Park, Lakshman Krishnamurthi, and Andris A. Zoltners. 1994. "Analysis of New Product Diffusion Using a Four-Segment Trial-Repeat Model." Marketing Science 13:224-47.

Hamerle, Alfred. 1990. "Simple Test for Neglected Heterogeneity in Panel Studies." Biometrics 46:193-99.

Han, Aaron, and Jerry A. Hausman. 1990. "Flexible Parametric Estimation of Duration and Competing Risk Models." Journal of Applied Econometrics 5:1-28.

Hannan, Timothy H., and John M. McDowell. 1987. "Rival Precedence and the Dynamics of Technology Adoption: An Empirical Analysis." Economica 54:155-71.

Harris, Jerome J. 1966. "Survey of Medical Communication Sources Available for Continuing Physician Education." Journal of Medical Education 41:737-55.

Haunschild, Pamela R., and Anne S. Miner. 1997. "Modes of Interorganizational Imitation: The Effects of Outcome Salience and Uncertainty." Administrative Science Quarterly 42:472-500. 


\section{American Journal of Sociology}

Hawkins, Norman G. 1959. "The Detailman and Preference Behavior." Southwestern Social Science Quarterly 40 (December): 213-24.

Hedström, Peter. 1994. "Contagious Collectivities: On the Spatial Diffusion of Swedish Trade Unions, 1890-1940.” American Journal of Sociology 99:1157-79.

Hurwitz, Mark A., and Richard E. Caves. 1988. "Persuasion or Information? Promotion and the Shares of Brand Name and Generic Pharmaceuticals." Journal of Law and Economics 31:299-320.

Kalish, Shlomo, and Gary L. Lilien. 1986. "Applications of Innovation Diffusion Models in Marketing." Pp. 235-79 in Innovation Diffusion Models of New Product Acceptance, edited by Vijay Mahajan and Yoram Wind. Cambridge, Mass.: Ballinger.

Katz, Elihu. 1961. "The Social Itinerary of Technical Change: Two Studies on the Diffusion of Innovation." Human Organization 20 (Summer): 70-82.

Katz, Elihu, and Paul F. Lazarsfeld. 1955. Personal Influence. Glencoe, Ill.: Free Press.

Katz, Michael L., and Carl Shapiro. 1994. "Systems Competition and Network Effects." Journal of Economic Perspectives 8:93-115.

Lilien, Gary L., Ambar Rao, and Shlomo Kalish. 1981. "Bayesian Estimation and Control of Detailing Effort in a Repeat Purchase Diffusion Environment." Management Science 27:493-506.

Marsden, Peter V., and Noah E. Friedkin. 1994. "Network Studies of Social Influence." Pp. 3-25 in Advances in Social Network Analysis: Research in the Social and Behavioral Sciences, edited by Stanley Wasserman and Joseph Galaskiewicz. Thousand Oaks, Calif.: Sage.

Marsden, Peter V., and Joel Podolny. 1990. "Dynamic Analysis of Network Diffusion Processes." Pp. 197-214 in Social Networks through Time, edited by Jeroen Weesie and Henk Flap. Utrecht: ISOR/Rijksuniversiteit Utrecht.

Menzel, Herbert, and Elihu Katz. 1955. "Social Relations and Innovation in the Medical Profession: The Epidemiology of a New Drug." Public Opinion Ouarterly 19:337-52.

Mines, Samuel. 1978. Pfizer. . . An Informal History. New York: Pfizer.

Montgomery, David B., and Alvin J. Silk. 1972. "Estimating Dynamic Effects of Market Communications Expenditures." Management Science, ser. B, 18:485-501.

Montgomery, Mark R., and John B. Casterline. 1996. "Social Learning, Social Influence, and New Models of Fertility." Population and Development Review 22 (suppl.): $151-75$.

Pearson, Michael. 1969. The Million-Dollar Bugs. New York: G.P. Putnam's Sons.

Peterson, Osler L., Leon P. Andrews, Robert S. Spain, and Bernard G. Greenburg. 1956. "An Analytical Study of North Carolina General Practice: 1953-54." Journal of Medical Education 31 (December): 1-165.

Rangaswamy, Arvind, and Lakshman Krishnamurthi. 1991. "Response Function Estimation Using the Equity Estimator." Journal of Marketing Research 28:72-83.

Rizzo, John A. 1999. "Advertising and Competition in the Ethical Pharmaceutical Industry: The Case of Antihypertensive Drugs." Journal of Law and Economics 42: 89-116.

Roberts, John H., and Glen L. Urban. 1988. "Modeling Multiattribute Utility, Risk, and Belief Dynamics for New Consumer Durable Brand Choice." Management Science 34:167-85.

Rogers, Everett M. 1994. A History of Communication Study: A Biographical Approach. New York: Free Press.

1995. Diffusion of Innovations, 4th ed. New York: Free Press.

Shankar, Venkatesh, Gregory S. Carpenter, and Lakshman Krishnamurthi. 1998. "Late Mover Advantage: How Innovative Late Entrants Outsell Pioneers." Journal of Marketing Research 35:54-70.

Strang, David. 1991. "Adding Social Structure to Diffusion Models: An Event History Framework." Sociological Methods and Research 19:324-53. 


\section{Contagion versus Marketing}

Strang, David, and Nancy Brandon Tuma. 1993. "Spatial and Temporal Heterogeneity in Diffusion." American Journal of Sociology 99:614-39.

Taibleson, Mitchell H. 1974. "Distinguishing between Contagion, Heterogeneity, and Randomness in Stochastic Models." American Sociological Review 39:877-80.

Thirtle, Colin G., and Vernon W. Ruttan. 1987. The Role of Demand and Supply in the Generation and Diffusion of Technical Change. Chur: Harwood Academic.

Valente, Thomas W. 1996. "Social Network Thresholds in the Diffusion of Innovations." Social Networks 18:69-89.

Van den Bulte, Christophe, and Gary L. Lilien. 1999. "Integrating Models of Innovation Adoption: Social Contagion, Utility Maximization, and Hazard Models.” Working Paper 99-021. University of Pennsylvania, Wharton School, Marketing Department. van Waterschoot, Walter, and Christophe Van den Bulte. 1992. "The 4P-Classification of the Marketing Mix Revisited." Journal of Marketing 56 (October): 83-93.

Weber, Max. (1921) 1968. Economy and Society. Translated by G. Roth and C. Wittich. Totowa, N.J.: Bedminster Press.

Winick, Charles. 1961. "The Diffusion of an Innovation among Physicians in a Large City." Sociometry 24:384-396. 